\title{
Mind Genomics to Teach Critical Thinking and Prepare Job Candidates for Interviews
}

\author{
Attila Gere', Roger Shelley², Sharon Starke ${ }^{3}$, Robert Sherman ${ }^{4}$, Vivek Jaiswal ${ }^{5}$ and Howard Moskowitz ${ }^{*}$ \\ ${ }^{1}$ Szent Istvan University, Budapest, Hungary \\ ${ }^{2}$ The Shelley Group, LLC, Greenwich, CT USA \\ 3Starke Solutions, Inc., Miami, FL USA \\ ${ }^{4}$ Robert Sherman Programming, Laguna Niguel, CA, USA \\ ${ }^{5}$ Vivek Jaiswal, Queens, New York, USA \\ ${ }^{6}$ Mind Genomics Associates Inc., White Plains, NY, USA \& Szent Isvan University, Budapest, Hungary \\ ^Corresponding Author: Howard Moskowitz, Mind Genomics Associates Inc., White Plains, NY, USA \& Szent Isvan University, Budapest, Hungary; E-Mail: mjihrm@ \\ sprynet.com
}

Received: September 30, 2019; Accepted: October 10, 2019; Published: October 23, 2019;

\begin{abstract}
We present a new approach to help students prepare for interviews. The approach applies a user-friendly app (BimiLeap) developed from the science of Mind Genomics. The app teaches students how to think critically and creatively, in a structured way, with feedback from panel respondents unknown to the student. From the viewpoint of the student as job applicant, the Mind Genomics approach can teach the applicant, a prospective employee to think better, and while learning to do so, help the applicant create an individual portfolio of studies that can be presented to the interviewer. The portfolio demonstrates the applicant's ability to do independent research relevant to the company doing the hiring. From the viewpoint of the hiring company, the Mind Genomics approach provides a test of intellectual proficiency, either as a homework assignment before the interview or as a test given to the respondent with the topic chosen by the interviewing company.
\end{abstract}

\section{Introduction}

As of this writing, there is an increasingly competitive environment for jobs [1]. Many papers are appearing decrying the nature of education as not preparing a person for the job [2]. The popular press, especially the Internet is a treasure of Cassandra-like predictions of the world of jobs which faces us during the next ten years. The issues are legion; hyper-competition, automation will make many of today's jobs irrelevant, and that the new work environment is making the world one of 'gigs; rather than lifetime employment and corporate loyalty. The job applicant will no doubt face a different world. Coupled with the structural changes of competition and automation is the reality that in many any cases the applications for jobs are screened by machine. There may be dozens if not hundreds of applicants for the same job. The hyper-competition breeds frustration, demoralization, and at the worse, the conscious decision simply to drop out of the job world, and no-launch career. The foregoing is reflected both in the academic and in the popular literature $[3,4]$. The loss of hope is an emerging problem for many countries, and the foreshadows the specter of a country slowly depopulating as the young people flee the country to more opportunities elsewhere.

\section{The World of Job Seeking Today}

The popular as well as the academic literature are replete with advice about how to prepare for jobs. Indeed, in Google Scholar ${ }^{\circ}$, the phrase 'preparing for a job interview' generates approximately 744,000 hits as of this writing (Summer 2019.) Going one step further, the phrase 'practical guide for job interview' generated 944,000 hits. The number of hits in Google itself is much greater, and the different facets of jobs as subtopics to search becomes overwhelming. There is a dual problem as well, the problem faced by the hiring group and by the interviewer. The problem is simply how to cut through the façade thrown up by the job seeker, to find out the who the job seeker 'really is' and what the job seeker can 'really do.' The issues facing the interviewer in the job interview range from understanding the true abilities of the candidate to avoiding emotional manipulation by the candidate. The notion of manipulation as a topic is widespread in the academic literature for the simple reason that the job interview is a critical event in the life of the job seeker [5]. It is not harder to understand that almost all job seekers will present themselves in the best possible light, taking credit for successes, and avoiding the very mention of a failure. The old adage works here 'success has many fathers but failure is an orphan'. How then can the interviewer probe more deeply into the mind of the respondent, to understand the thinking capability of the respondent?

\section{How Mind Genomics Works and its Application to the Interview Process}

We present here a suggestion, based upon the developing research of Mind Genomics, and the now readily available app, www.BimiLeap. com. The basic idea is that the Mind Genomics approach, described below, becomes a tool, either to produce interesting, relevant knowledge 
which distinguishes the candidate from the other candidates by virtue of the effort, or its dual, a method to assess the thinking capabilities of the candidate at the time of the interview, thus avoiding the effort to deconstruct letters of reference in what's true and what's hyperbole. The spirit of using computers for interviews is not new but what is new is the use of the computer both to prepare the student and to test the student, using the same technology. The preparation is not 'test preparation' but rather education to think in a critical way. The test is not standard testing and performance, but rather demonstration of ability to solve a new problem, on demand, using critical thinking. Can experimentation increase both the likelihood of getting a specific job, but also the ability of the job applicant to 'think', preparing for a career where change is the only constant? In previous papers by this team of researchers, the notion has been offered that there is a structured way to think, one which can apply to the creation of a bank of knowledge about how we make everyday decision. The approach is Mind Genomics, a method which allows the researcher to combine different ideas according to experimental design [6], obtain responses from subjects, and then determine which specific ideas drive the decision. We present Mind Genomics from the viewpoint of preparing students, really applicants in general, an idea which goes back decades, and comprises a variety of approaches [7].

Mind Genomics has been used in areas ranging from politics to food to medicine to law and so forth [8]. The studies are serious, scientific studies, which form part of an emerging archive of knowledge about the world of the everyday and decision-making. It is the suggestion of the authors that the very same approach to knowledge might be well-used by the job seeker, both to train her or his mind, but also to provide material of immediate relevance and important to the interview. The remainder of this paper demonstrates the application, results which are of immediately interest to the interviewer as well as being a scientific contribution, and finally data which suggest a process to teach the job applicant, how to think. Mind Genomics traces its history to both mathematical psychology [9], and to marketing research $[10,11]$. These early studies investigated how people mentally 'weight; different factors to arrive at a decision. The early studies worked on either simplistic problems with academic rigor but little practical application, or on large-scale problems in marketing. The early processes were cumbersome, requiring that respondent either choose one of two test stimuli of different combinations of features, or rate known combinations of features.

More recent efforts have focused on creating simpler, rapid, and user-friendly methods which can be adapted to an app (www. BimiLeap.com), and in turn widely used by those who are not academically oriented to publish papers, but rather need the information for practical decisions. The evolution of the science of Mind Genomics has expanded the applications, making them easy, archival, usable by anyone from age 8-9 and older. Mind Genomics follows these straightforward steps. Where relevant, the steps can be embedded in the interview process.

\section{Step 1 - Define a Topic or A Problem}

The interviewer can define a problem before or during the interview, or the job seeker can exercise initiative and define the problem. The problem selected for this study is: 'What attracts a prospective job seeker to select a training/placement company?'

\section{Step 2 - Create a Structure by Asking Four Questions Which 'Tell a Story'}

This is the Socratic approach, of asking and answering questions. Table 1 shows the four questions for this project.

Table 1. The topic, the four questions and the four answers to each question

\begin{tabular}{|c|c|}
\hline & $\begin{array}{l}\text { Topic: What attracts a prospective job seeker to select a training/ } \\
\text { placement company?' }\end{array}$ \\
\hline & $\begin{array}{l}\text { Question } 1 \text { - How does the company satisfy client needs for trained } \\
\text { personnel? }\end{array}$ \\
\hline A1 & $\begin{array}{l}\text { Uses multiple sourcing options...e.g., relationship-marketing, social media } \\
\text { and advertising }\end{array}$ \\
\hline A2 & Hires temp contract workers until right candidate found \\
\hline A3 & Educational program to train potential candidate \\
\hline \multirow[t]{2}{*}{ A4 } & Willing to invest more for the right talent \\
\hline & Question B: How does the company customize the process for the client? \\
\hline B1 & Sound interview process, including direct contact with the hiring manager \\
\hline B2 & Understands the biggest deciding factor for the candidate \\
\hline B3 & Involves upper management in meetings \\
\hline \multirow[t]{2}{*}{ B4 } & $\begin{array}{l}\text { Streamlines the process, beat competition by moving quicker in hiring } \\
\text { process }\end{array}$ \\
\hline & $\begin{array}{l}\text { Question C: What up-to-date technologies does the company adopt in } \\
\text { order to be effective? }\end{array}$ \\
\hline $\mathrm{C} 1$ & Uses centralized data \& analytics \\
\hline $\mathrm{C} 2$ & Uses most updated hiring technologies \\
\hline $\mathrm{C} 3$ & Uses cloud-based tools ... automate and manage process \\
\hline \multirow[t]{2}{*}{$\mathrm{C} 4$} & $\begin{array}{l}\text { Work with hiring managers to understand technicalities and screen for best } \\
\text { fit }\end{array}$ \\
\hline & $\begin{array}{l}\text { Question D: How does the company stay 'close' to its client to anticipate } \\
\text { needs? }\end{array}$ \\
\hline D1 & Communicate with corporate managers ... define needed skill sets \\
\hline D2 & $\begin{array}{l}\text { Builds relationship and rapport with corporate managers ... set right } \\
\text { expectations }\end{array}$ \\
\hline D3 & Emphasizes why speed important ... to find right candidate who fits \\
\hline $\mathrm{D} 4$ & Build appropriate training plans ... from hiring manager's input \\
\hline
\end{tabular}

\section{Step 3 - Provide Four Answers for Each Question}

Typically, these questions and answers are provided by the job candidate. To the degree that the candidate can provide clearly thought-out, relevant, and different answers, one may surmise that the candidate can think in a structured way. Table 1 shows the four answers provided by one job candidate. At this point it is important to note that the system enables the job candidate to demonstrate his or her proficiency and knowledge about the topic, about the company, or about a discipline in which the candidate has been involved. 
The actual task of creating the material may be given to the job candidate in at least two ways:

a. The candidate may receive the topic, but the candidate should provide both the questions and the answers. This entire sequence of events, from receiving the topic to providing the questions and answers, to executing the study could then reveal whether the candidate has the intellectual capability to follow instructions, yet think critically, and execute a study.

b. The candidate may receive the topic at the time of interview and be give a fixed number of hours to run the actual study under supervision, as part of an interview. It would probably be a good idea for the candidate to 'train' on the mechanics of the process before the interview, doing so in a relaxed manner, in privacy, free to make mistakes. The actual test would be supervised, however.

\section{Step 4: Combine The Elements (Answers) Into Vignettes According to An Experimental Design}

The elements comprise single ideas. Mind Genomics combines these single ideas into vignettes, i.e., vignettes, comprising 2-4 ideas (elements, answers), with at most one element from each question, but often no elements or answers from a question. To the outsider looking at the 24 vignettes specified by the experimental design it might appear that the elements are thrown together at random. Nothing could be further from the truth. The experimental design is a planned set of vignettes with the property that each element appears an equal number of times against different backgrounds provided by the elements from the other questions. Furthermore, the 16 elements or answers are statistically independent of each other, allowing the ratings to be collected from individual respondents to be 'linked' to the presence/absence of the individual respondent ratings. Finally, and very important, is the feature that the set of specific test vignettes for each respondent different from the specific test vignette of every other respondent. This pattern, so-called permuted design [12], allows the research to cover a wide number of vignettes in the 'design space.' The metaphor here is the tightness of estimation by testing a lot of different vignettes, each with error but with the total pattern studied, rather than obtaining tight estimations by replicating the number of judgments on a small set of vignettes presumed to represent the larger array of vignettes. In a sense, Mind Genomics is an MRi of the mind, taking different pictures by responses to vignettes. Figure 1 shows an example of a vignette.

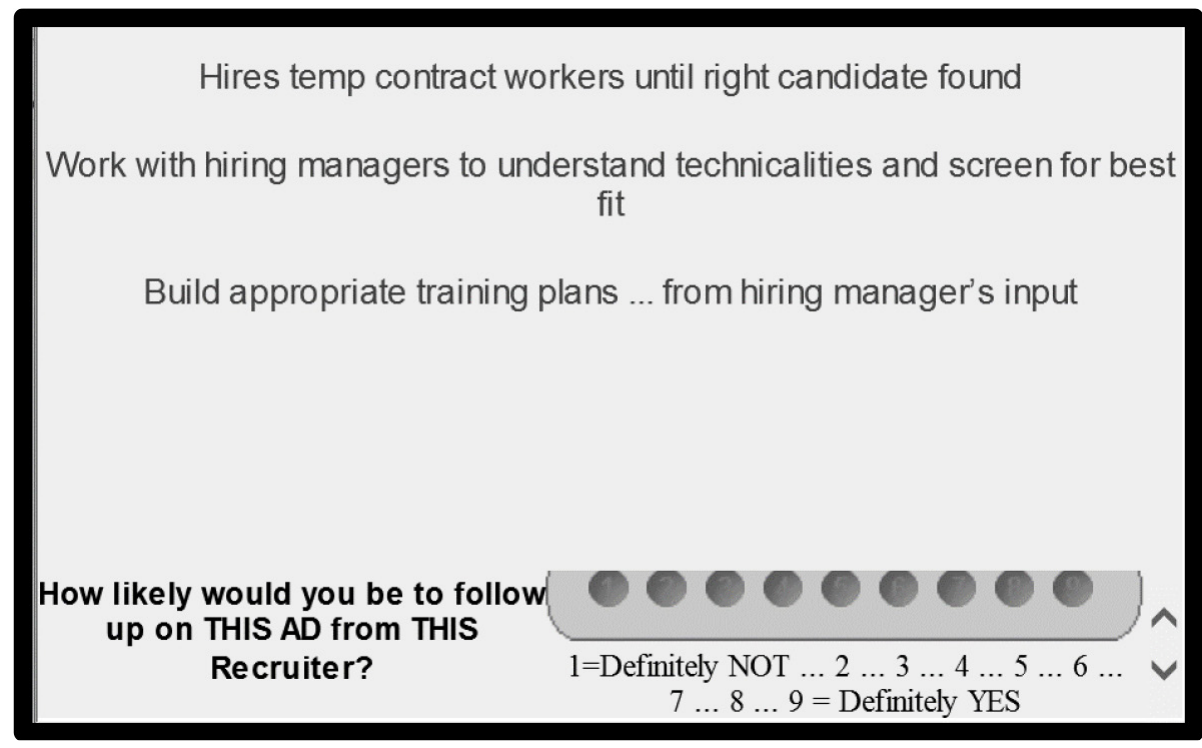

Figure 1. Example of a vignette comprising three elements, and the rating scale on the bottom of the screen shot.

\section{Step 5: Self-Profiling Classification}

At the end of the evaluation, the respondent completed an extensive classification questionnaire, allowing the research to obtain more information about the respondent, in terms of who the respondent IS, what the respondent BELIEVES, and so forth. For this project we present only three of the questions, age, gender, and general response to the vignettes. The data appear in Table 2.

\section{Step 6 - Transform The 9-Point Rating Scale Into A Binary Scale (0/100)}

The transformation allows the use of the research results to better understand the meaning of the data. Although there is more precision in the 9-point scale than in the binary scale, simply because of the granularity of the results, most users of the research do not know how to work with Likert scales, the reason being that Likert scales do not promote decision-making. To make the data easy to interpret and easy to act upon, we transform the data, dividing the 9-point scale into two halves. The upper half comprises the ratings of 7-9, and ia recoded to 100 (plus a very small random number, for regression as explained below.) The recode to ' 100 ' signifies 'YES'. The lower half comprises 
the ratings of $1-6$, and is recoded to 0 (plus a very small random number), to signify 'NO'.

Table 2. Self-profiling classification of the respondents who participated

\begin{tabular}{|c|c|c|}
\hline & $\mathbf{N}$ & $\%$ \\
\hline \multicolumn{3}{|c|}{ Q1: Please indicate your gender. } \\
\hline Male & 30 & $57 \%$ \\
\hline Female & 23 & $43 \%$ \\
\hline \multicolumn{3}{|c|}{ Q2: Which of the following best describes your age? } \\
\hline Under 18 & 0 & $0 \%$ \\
\hline 18 to 24 & 2 & $4 \%$ \\
\hline 25 to 34 & 21 & $40 \%$ \\
\hline 35 to 44 & 14 & $26 \%$ \\
\hline 45 to 54 & 6 & $11 \%$ \\
\hline 55 to 64 & 6 & $11 \%$ \\
\hline 65 and older & 4 & $8 \%$ \\
\hline \multicolumn{3}{|c|}{$\begin{array}{l}\text { Q3: Based on all the ads that you saw, how interested would you be in applying for } \\
\text { a new job at this type of company? }\end{array}$} \\
\hline $1=$ Not interested & 3 & $6 \%$ \\
\hline $2=$ Maybe & 36 & $68 \%$ \\
\hline $3=$ For sure & 14 & $26 \%$ \\
\hline
\end{tabular}

Step 7 - Use OLS (Ordinary Least-Squares) Regression To Relate The Presence/Absence Of Each Of The $\mathbf{1 6}$ Elements To The Binary Recoded Data

OLS regression deconstructs the rating into a simple linear model: Binary Rating $=\mathrm{k}_{0}+\mathrm{k}_{1}(\mathrm{~A} 1) \ldots \mathrm{k}_{16}(\mathrm{D} 4)$. Each element generates a unique coefficient. The additive constant, $\mathrm{k}_{0}$, is the estimated binary value in the absence of elements, a purely hypothetical situation. All vignettes by design comprised 2-4 elements, so the additive constant can be considered a baseline., i.e., the inherent predisposition to say 'YES'.

\section{Step 8 - Compute The Parameters Of The Model For Total Panel, For Key Subgroups As They Define Themselves, And For Mind-Sets (Explained Below)}

Table 3 presents the summary of coefficients for total, gender, and age. All coefficients of 15 or higher are shown in shaded cells, and bold type. The additive constant tells us the likelihood of 'following up with this recruiter.' Since the ratings were transformed to their binary values, the additive constant tells us the likely percent of responses that would be 'YES, I'd follow up with this recruiter,' assuming the three highest ratings, 7-9, signify 'YES.' What emerges as fascinating is the lack of confidence without supporting evidence, with the only respondents 'willing' to believe the recruiter even at all are the older respondents, and not really (additive constant $=11$.) It will be the individual elements which must do all the work.

Table 3. Performance of elements among total panel, genders, and ages

\begin{tabular}{|c|c|c|c|c|c|c|}
\hline & & Total & Male & Female & Age 25-34 & Age 35-44 \\
\hline & Base Size & 53 & 30 & 23 & 21 & 14 \\
\hline & Additive constant & -1 & -1 & -1 & -13 & 11 \\
\hline $\mathrm{B} 2$ & Understands the biggest deciding factor for the candidate & 21 & 29 & 10 & 16 & 29 \\
\hline B1 & Sound interview process, including direct contact with the hiring manager & 20 & 23 & 16 & 15 & 25 \\
\hline D4 & Build appropriate training plans ... from hiring manager's input & 19 & 14 & 25 & 20 & 14 \\
\hline $\mathrm{C} 4$ & Work with hiring managers to understand technicalities and screen for best fit & 18 & 15 & 21 & 17 & 16 \\
\hline A4 & Willing to invest more for the right talent & 17 & 16 & 19 & 22 & 11 \\
\hline A3 & Educational program to train potential candidate & 16 & 18 & 12 & 13 & 20 \\
\hline D2 & Builds relationship and rapport with corporate managers ... set right expectations & 15 & 16 & 12 & 20 & 5 \\
\hline B4 & Streamlines the process, beat competition by moving quicker in hiring process & 15 & 17 & 12 & 15 & 24 \\
\hline $\mathrm{C} 2$ & Uses most updated hiring technologies & 14 & 11 & 17 & 22 & 2 \\
\hline D1 & Communicate with corporate managers ... define needed skill sets & 13 & 10 & 16 & 12 & 16 \\
\hline B3 & Involves upper management in meetings & 11 & 19 & 1 & 6 & 20 \\
\hline A1 & Uses multiple sourcing options...e.g., relationship-marketing, social media and advertising & 10 & 11 & 9 & 10 & 20 \\
\hline D3 & Emphasizes why speed important ... to find right candidate who fits & 8 & 6 & 11 & 9 & 3 \\
\hline $\mathrm{C} 3$ & Uses cloud-based tools ... automate and manage process & 7 & 5 & 9 & 9 & 5 \\
\hline $\mathrm{C} 1$ & Uses centralized data $\&$ analytics & 7 & 7 & 6 & 12 & -3 \\
\hline $\mathrm{A} 2$ & Hires temp contract workers until right candidate found & 0 & 1 & -1 & 2 & 2 \\
\hline
\end{tabular}


The 16 elements are sorted in descending order, based upon the total sample.

a. Many of the elements perform very well. Previous studies and unpublished observations suggest that coefficients whose values are greater than +10 correspond to elements which drive positive decisions. These data reveal a cadre of elements which drive a strong positive reaction. Knowledge of these features should help the company and the prospective job candidate seeking to work with a training and recruiting company:

Understands the biggest deciding factor for the candidate

Sound interview process, including direct contact with the hiring manager

Build appropriate training plans ... from hiring manager's input

Work with hiring managers to understand technicalities and screen for best fit

Willing to invest more for the right talent

Educational program to train potential candidate

b. Genders differ. Males dramatically respond more to these elements:

Understands the biggest deciding factor for the candidate

Involves upper management in meetings c. Ages differ as well. Younger respondents respond strongly to technology and are sensitive to the opinion of higher-level managers

Uses most updated hiring technologies (22 for younger respondents, 2 for the older respondents)

Builds relationship and rapport with corporate managers ... set right expectations (20 for younger respondents, 5 for the older respondents)

\section{Dividing Respondents By Their Decisions And By Their Mind-Sets, Respectively}

The classification questionnaire, done at the end of the Mind Genomics experiment, allows the respondent to how she or he feels about the potential job. We first compare two out of the three selfdefined groups, those who say that they may follow up with the company they liked most $(n=36)$ and those who say that they are sure that they would follow up $(\mathrm{n}=14)$. Table 4 shows these results. Each group shows a very low additive constant, around 0 . Those who are 'sure' about following up show eight very strong elements, with coefficients of 20 or higher. However, there is no pattern which makes us 'smarter' about the mind of those who say that they would follow up. We know what works, but we cannot generate a rule, although we get a sense of focus on the job seeker and on a relationship with the hiring manager.

Table 4. Performance of elements among total panel, self-stated likelihood to use a company which provides the messages they like the most, and emergent mind-sets based upon the pattern of coefficients

\begin{tabular}{|c|c|c|c|c|c|c|}
\hline & & Total & Q3 Maybe & Q3 Sure & MS1 -People & MS2-Technology \\
\hline & Base Size & 53 & 36 & 14 & 28 & 25 \\
\hline & Additive constant & -1 & 1 & -5 & 3 & -5 \\
\hline & Mind-Set 1 - Empathic and People Oriented & & & & & \\
\hline B2 & Understands the biggest deciding factor for the candidate & 21 & 19 & 23 & 29 & 13 \\
\hline D4 & Build appropriate training plans ... from hiring manager's input & 19 & 17 & 23 & 21 & 17 \\
\hline D2 & Builds relationship and rapport with corporate managers ... set right expectations & 15 & 15 & 16 & 20 & 8 \\
\hline B1 & Sound interview process, including direct contact with the hiring manager & 20 & 18 & 24 & 18 & 21 \\
\hline A4 & Willing to invest more for the right talent & 17 & 17 & 17 & 18 & 16 \\
\hline \multirow[t]{2}{*}{ A3 } & Educational program to train potential candidate & 16 & 14 & 20 & 17 & 14 \\
\hline & Mind-Set 2 - Technology Oriented & & & & & \\
\hline $\mathrm{C} 4$ & Work with hiring managers to understand technicalities and screen for best fit & 18 & 19 & 22 & 8 & 28 \\
\hline B4 & Streamlines the process, beat competition by moving quicker in hiring process & 15 & 13 & 20 & 10 & 20 \\
\hline $\mathrm{C} 2$ & Uses most updated hiring technologies & 14 & 11 & 26 & 7 & 20 \\
\hline \multirow[t]{2}{*}{$\mathrm{C} 3$} & Uses cloud-based tools ... automate and manage process & 7 & 5 & 16 & -3 & 17 \\
\hline & Does not drive either mind-set & & & & & \\
\hline $\mathrm{A} 2$ & Hires temp contract workers until right candidate found & 0 & -3 & 7 & -12 & 14 \\
\hline A1 & Uses multiple sourcing options...e.g., relationship-marketing, social media and advertising & 10 & 5 & 23 & 7 & 13 \\
\hline D1 & Communicate with corporate managers ... define needed skill sets & 13 & 12 & 13 & 13 & 12 \\
\hline B3 & Involves upper management in meetings & 11 & 7 & 17 & 11 & 11 \\
\hline $\mathrm{C} 1$ & Uses centralized data \& analytics & 7 & 6 & 19 & 5 & 9 \\
\hline D3 & Emphasizes why speed important ... to find right candidate who fits & 8 & 8 & 9 & 13 & 2 \\
\hline
\end{tabular}


Uses most updated hiring technologies

Sound interview process, including direct contact with the hiring manager

Understands the biggest deciding factor for the candidate

Build appropriate training plans ... from hiring manager's input

Uses multiple sourcing options...e.g., relationship-marketing, social media and advertising

Work with hiring managers to understand technicalities and screen for best fit

Educational program to train potential candidate

Streamlines the process, beat competition by moving quicker in hiring process

Those say they 'might' follow up six strong elements, but all are lower than 20 .

Understands the biggest deciding factor for the candidate

Work with hiring managers to understand technicalities and screen for best fit

Sound interview process, including direct contact with the hiring manager

Build appropriate training plans ... from hiring manager's input

Willing to invest more for the right talent

Builds relationship and rapport with corporate managers ... set right expectations

It is important to note that with these data we see no interest in companies with technology as their focus. Rather, we sense that the general pattern is focus on the candidate, on the human aspect. We will see that this picture of the mind of the job seeker is only halfrevealed by standard questions about interest. We will see in a moment that there is another mind-set, technology-oriented, comprising half the population of respondents, but hidden until revealed by the extraction of mind-sets. A far stronger approach to finding differences among people in the population looks at the pattern of their individual coefficients, with the attempt to identify groups of individuals with radically different ways of thinking about the same elements or messages. The segmentation method, clustering, has been well described in the statistics literature [13] and is a mainstay of the Mind Genomics armory. The key is to focus on a micro-area, such as the offerings of the technology personnel company, rather than focusing on a grand division of people. When the segmentation is done on the pattern of coefficients for this 'micro-topic', the results are often dramatic, clear, and compelling. Table 4 shows the coefficients from the two mind-sets. It is clear from Table 4 that Mind-Set 1 comprises individuals who respond to a company which is empathic, and people oriented. Mind-Set 2 comprises individuals who respond to a company which is technology oriented. The differences between the two mind-sets is clear, dramatic, and easy to interpret.

\section{Finding These Mind-Sets In The Population}

The mind-sets distribute in the population in ways that cannot be easily predicted. In some occasions we might be sufficiently fortunate to find a co-variation between mind-set membership and some other easily defined. That happy event is not the usual case. Rather, the mind-sets might distribute in a slightly uneven pattern, but not a pattern upon which one could readily rely when assigning individuals to mind-sets for a topic. Except for very common topics it is quite unlikely that there will be either any data on a specific, newly discovered mind-set, such data dealing either with the nature of the mind-set, or the rules to discover individuals with the mind-set. The topics are too small, too focused, too specific, too 'local' for general studies of more 'global' mind-sets [14]. A different way is needed, one which is grounded in speed, ease, low-cost, and can be adapted quickly to any data set of the type found by Mind Genomics. Recent efforts by author Gere suggest that such a method can be created. The approach is based upon a Monte Carlo simulation of assignments to one of two or one of three mind-sets, based upon the mean coefficients by mind-set of six elements (here 6 of 16). The coefficients are perturbed by noise and searched to identify the elements which most strongly differentiate among the segments. The method creates a set of six 'questions,' using the text of the individual elements, creates two answers, and computes the 64 possible patterns. That approach, done 20,000 times in a Monte Carlo simulation, identifies the best six elements, and the most likely mind-set corresponding to each of the 64 possible binary patterns. Figure 2 shows an example of the PVI, the personal viewpoint identifier. The PVI expands the use of the study when the results are to be used to understand prospective clients of the customer. By knowing the mind-set to which each person belongs, one can tailor the appropriate program for the specific individual who has signed on as a client. Furthermore, by knowing the mind-set to which a prospect belongs, the company can send the appropriate messages to convert the prospect to a client.

\section{Discussion - Technical Aids To Creating A Personal Portfolio}

When one thinks about the strategies for interviewing, for getting a job, the notion of doing a 'pilot study' may seem strange as a way to 'market oneself'. Yet, such marketing may become necessary in the evolving world where the combination of critical thinking and ability to do data analytics could be a key part of self-marketing. As far back as 2003 the notion of 'self-marketing' was becoming increasingly relevant to students looking for jobs [1]. Fifteen years before, it was already an issue in the world of business schools [2]. The pilot study does not present an individual's credentials, nor show the individual as a person. Or, in fact, does it? In the world of academics, one often does not proceed with research before one writes a proposal about the research. Quite frequently, it is necessary to buttress that proposal with some preliminary data to show that the approach proposed with come up with meaningful results. Indeed, it is often the case that one must do a study and complete it, doing so surreptitiously, presenting the findings in a proposal, in order to get funding for the study. That is, the study must be presented in proposal form, but with data guaranteeing the success of the project. We suggest here that the thinking of pilot projects as preliminaries to a big project be adopted for job seeking. What has been missing up to now may be an inexpensive, simple, rapid way to do these pilot projects, a way which can demonstrate 
the capabilities of the job applicant. We suggest that the approach presented here may be expanded to be of use to screen applicants. The screening might be done in two ways, as suggested in the introduction to this paper:

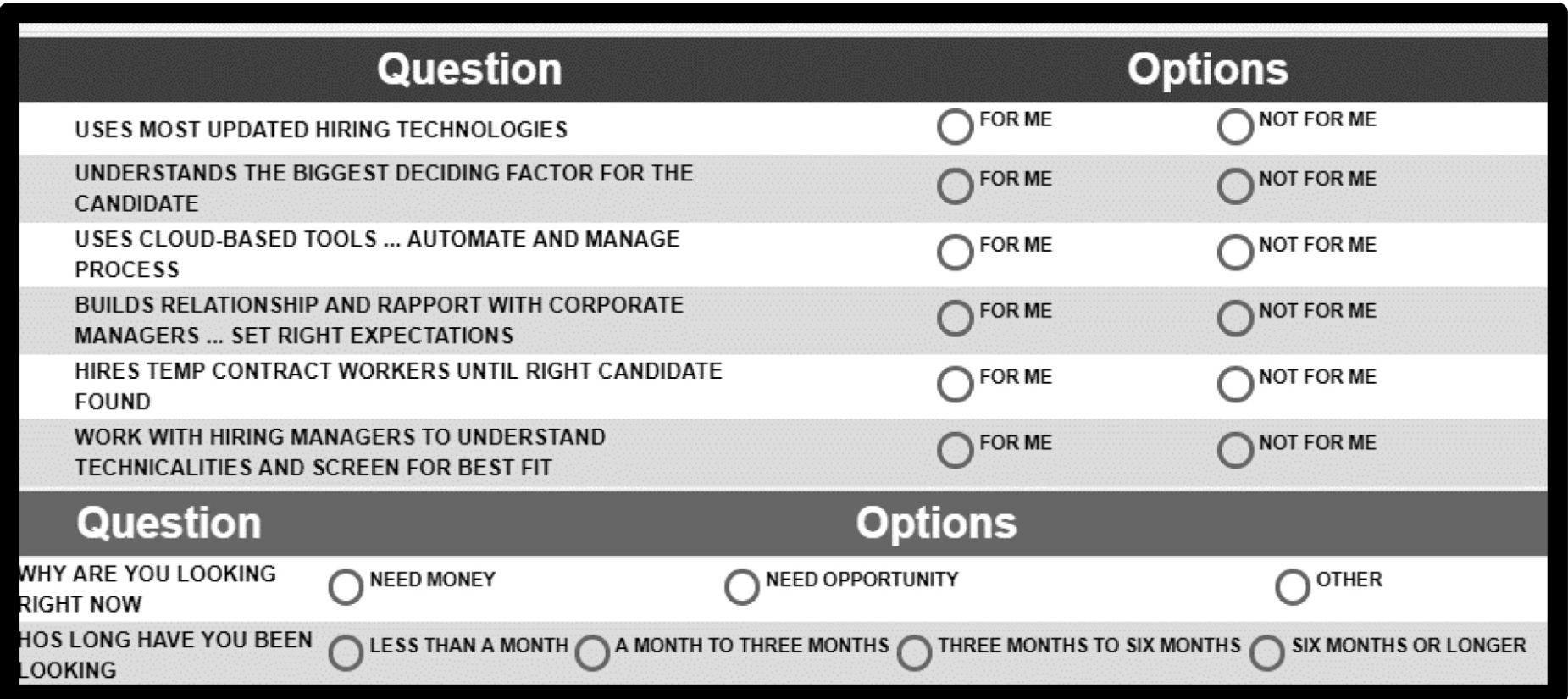

Figure 2. The PVI (personal viewpoint identifier), created to assign a new person to one of the two mind-sets uncovered in this study

HOMEWORK: The Company presents the job applicant with a problem and gives the applicant a week to come up with the specific topic, the four questions, and the four answers to each question. If the job applicant appears to have provided an appropriate set of questions and answer, the company may decide to hire the candidate, even without running the study, simply on the basis of the homework done by the applicant.

ON-SITE PERFORMANCE TEST: This performance test may be done in a defined time period, e.g., five hours, from start to finish, either with the respondent at home, or in the corporate office. In a very strongly competitive market, he company may invite all candidates into a central test site, a room full of candidates with computers, give the candidates specific topic, instruct them to set up the study, run the study, each with 50-100 respondents (paid for by the company), get the results in perhaps two or three hours. The next step would be to measure the quality of the candidate's thinking by looking at the performance of the elements, the performance of the elements by subgroup, and indeed whether or not the candidate's actual study has been able to identify new, interesting, and potentially relevant mindsets. Such a candidate would stand out as promising. The benefits are both a real-life test of abilities, and a possible crowd-sourced solution to a problem faced by the company, with the 'crowd' comprising the job applicants 'doing the thinking' and the respondents (unknown to anyone, but real people), providing evaluations of what to them are real and meaningful ideas involved with a problem.

\section{Acknowledgement}

Attila Gere thanks the support of Premium Postdoctoral Research Program of the Hungarian Academy of Sciences.

\section{References}

1. Taylor KA (2003) Marketing yourself in the competitive job market: An innovative course preparing undergraduates for marketing careers. Journal of Marketing Education 25: 97-107.

2. Buckley MR, Peach EB, Weitzel W (1989) Are collegiate business programs adequately preparing students for the business world? Journal of Education for Business 65: 101-105.

3. Hansen K, Oliphant GC, Oliphant BJ, Hansen RS (2009) Best practices in preparing students for mock interviews. Business Communication Quarterly 72: 318-327.

4. Krannich CR, Krannich RL (1990) Interview for Success. Impact Publications.

5. Baron RA (1997) Impression Management, Fairness, \& the Employment. Journal of Business Ethics 16: 801-810.

6. Box GE, Hunter WG, Hunter JS (1978) Statistics for experimenters, New York, John Wiley.

7. Latham GP, Saari LM, Pursell ED, Campion MA (1980) The situational interview. Journal of Applied Psychology 65: 422-427.

8. Moskowitz HR, Gofman A (2007) Selling blue elephants: How to make great products that people want before they even know they want them. Pearson Education.

9. Luce, R.D. \& Tukey, J.W., 1964. Simultaneous conjoint measurement: A new type of fundamental measurement. Journal of mathematical psychology 1: 1-27.

10. Green PE, Rao VR (1971) Conjoint measurement for quantifying judgmental data. Journal of marketing research 8: 355-363.

11. Green PE, Srinivasan V (1990) Conjoint analysis in marketing: new developments with implications for Research \& practice. The Journal of Marketing 54: 3-19.

12. Gofman A, Moskowitz H (2010) Isomorphic permuted experimental designs \& their application in conjoint analysis. Journal of Sensory Studies 25: 127-145.

13. Dubes RC, Jain AK (1988) Algorithms for Clustering Data. Prentice Hall.

14. Weinstein A, Cahill DJ (2014) Lifestyle Market Segmentation. Routledge.

Citation:

Gere A, Shelley R, Starke S, Sherman R, JaiswalV and Moskowitz H (2019) Mind Genomics to Teach Critical Thinking and Prepare Job Candidates for Interviews. Ageing Sci Ment Health Stud Volume 3(5): 1-7. 